\title{
Market Perceptions of US and European Policy Actions Around the Subprime Crisis
}

\author{
Theoharry Grammatikos \\ Thorsten Lehnert \\ and \\ Yoichi Otsubo* \\ Luxembourg School of Finance \\ University of Luxembourg
}

First version: August 2012

\begin{abstract}
This paper explores the impacts of key policy actions by US and European authorities on stock returns of systemically important banks in Europe and US around the subprime crisis. We find that the US policy announcements had a stronger impact on the European and US banking industry than the European policy announcements. In particular, the announcements of monetary policies and financial sector policies by the US authorities were accompanied by higher abnormal returns compared to related announcements of European authorities while the announcements of the US liability guarantees had the most favorable impact on the banking stock returns during the crisis. The lead role of US policies compared to European policies was strengthened after the collapse of Lehman brothers. We also find that the policy announcements, regardless of which side of the Atlantic the news arrived from, has increased the return volatility during the crisis. Our results lend additional support to the literature documenting event-induced volatility increases.
\end{abstract}

Keywords: Event study; Policy Announcement; Subprime crisis;

JEL Classification: G01, G14, G18, G21, G28

\footnotetext{
${ }^{*}$ Corresponding author. Luxembourg School of Finance, University of Luxembourg, 4, rue Albert Borschette, L-1246 Luxembourg, Luxembourg, tel. +352466644-6886; fax +352466644-6835. E-mail addresses: Theoharry . Grammatikos@uni.lu (T. Grammatikos); Thorsten.Lehnert@uni.lu (T. Lehnert); yoichi.otsubo@uni.lu (Y. Otsubo).
} 


\section{Introduction}

Since the onset of the subprime mortgage crisis in 2007 governments and central banks in the US and Europe have taken a number of actions to remedy the situation. Their policy actions include fiscal stimulus packages, monetary policies (e.g. Fed funds interest rate cut to near zero on 12.16.2008), liquidity supports (e.g. U.S. Term Auction Facility on 12.12.2007 and 12.21.2007; ECB liquidity injection on 08.09.2007), financial sector policies (e.g. U.S. Troubled Assets Relief Program on 10.03.2008) and other measures such as bailouts and assisted mergers (e.g. SachsenLB capital injection on 08.02.2007; Northern Rock liquidity support facility on 09.14.2007; Merril Lynch sale to Bank of America on 09.15.2008).

In this paper we analyze how the respective stock markets, banking stocks in particular, perceived those policy actions from the two sides of the Atlantic. To that end we use the policy news database constructed by Aït-Sahalia, Andritzky, Jobst, Nowak and Tamirisa (2012) to investigate the immediate reactions of systemically important banking stock across Europe and US. In particular we analyze the abnormal returns and the induced volatilities corresponding to the several types of key policy announcements by US and European authorities during the crisis as identified by Aït-Sahalia et al. (2012). The financial crisis has impaired the whole stock market but has especially destabilized the banking sector. The market reactions to the various policy announcements are of great interest to the scholars and the policy makers seeking the best ways to reverse the negative market sentiment and to halt the economic contagion.

The dynamics of the stock prices during the crisis period indicate strong heteroskedastic volatility and cross-sectionally diverged volatility which would impair the power of the traditional tests of significance of the abnormal returns. Our empirical strategy is based on the exponential general autoregressive conditional heteroskedastic (EGARCH) model with announcement dummies which is a variant of the approach suggested by Savickas (2003). This approach is a natural one given our focus on how policy announcements affect stock returns and volatility under serially heteroskedastic volatility.

Furthermore, the crisis period is dotted with a large number of potentially important announcements from the US and European authorities which refer to different policy types or policy mixes. They exhibit a large degree of clustering overtime which implies that using event windows of a few 
days around each announcement, as is typically done in event studies, would result in overlapping events rendering the interpretation of the results quite difficult. To reduce the number of overlapping events we thus focus only on the immediate stock response on the announcement day, i.e., we use a one-day event window. Hence this study is an investigation of immediate market responses to policy announcements and does not aim to provide an analysis on the long-term effectiveness of policies.

Several studies examine the role of policy actions during the recent subprime mortgage crisis. See for example McAndrews, Sarkar and Wang (2008), Baba and Packer (2009), Panetta, Faeh, Grande, Ho, King, Levy, Signoretti, Taboga and Zaghini (2009) and Taylor and Williams (2009). The two papers most closely related to our own are King (2009) and Aït-Sahalia, Andritzky, Jobst, Nowak and Tamirisa (2012). King (2009) studies the market reaction around the subprime crisis particularly to bank rescue packages announced in six countries and shows that bank stock prices continued to underperform in all countries except US. The traditional event study methodology with 100 day event windows used by the author does not consider serial heteroskedasticity, event induced volatility and overlapping events. Aït-Sahalia et al. (2012) construct a detailed database of macroeconomic and financial sector policy initiatives, also employed in this paper, and investigate the impact of policy announcements in the US, UK, the euro area, and Japan during the subprime mortgage crisis. Their focus though is different. To examine the impact on interbank credit and liquidity risk premia they analyze the immediate response on the Libor-OIS spread. Like King (2009), they do not address the problem of serial heteroskedasticity and event induced volatility.

Our findings suggest that overall US policy announcements had a stronger impact on the banking industry than European policy announcements. In particular, the announcements of monetary policies and financial sector policies by the US authorities were accompanied by higher abnormal returns compared to related announcements of the European authorities while the announcements of the US liability guarantees had the most favorable impact on the banking stock returns during the crisis. The findings are in line with the literature documenting that the US news affect the behavior of asset prices around the world but that the opposite is not true (Andersen et al. 2003, Becker et al. 1995, Ehramann and Fratzscher 2003, Wongswan, 2006). We also find that the policy announcements, regardless of which side of the Atlantic the news arrived from, have increased the return volatility during the crisis. Our results lend additional support to the literature documenting 
event-induced volatility increases (Savickas 2003, Harrington and Shrider 2007).

The paper is organized as follows. Section 2 describes the policy announcements and data. Section 3 explains our econometric approach for estimating the impact of policy actions. Section 4 reports our empirical results while Section 5 concludes with a summary of our findings.

\section{Policy Announcements and Stock Data}

\subsection{Policy Announcements}

The policy event database we apply is constructed by Aït-Sahalia et al. (2012) and covers major policy announcements from 06.01.2007 to 03.31.2009 by the authorities in the United States, the United Kingdom, and the euro area during the subprime financial crisis. The events sample is subdivided into a Pre-Lehman period (06.01.2007 to 09.12.2008) and a Post-Lehman period (09.15.2008 to 03.31.2009). Policy announcements in the euro area contain those by the European Central Bank (ECB) and country authorities from Austria, Belgium, France, Germany, Ireland, Italy, the Netherlands, and Spain. The policy announcements included are those which are considered as watershed policy events. To identify major policy events the authors search front-page articles where the policy announcement is the main subject. Announcements appearing as front-page news one day before and up to three days after the date of the official announcement are qualified as watershed events.

The policy announcements are next classified in six groups: fiscal policies; monetary policies; liquidity supports; financial sector policies; policy inaction and bailouts/failures; other measures. Each group, except fiscal policies and other measures, is further subdivided so that the policies are ultimately divided into twelve categories. The number of policy event days for each category is reported in Table 1.

\section{[Insert Table 1]}

Fiscal policies are economic stimulus measures such as public spending, tax reductions and job creation associated with an expansion in government expenditures.

Monetary policies are categorized in two groups, interest rate cuts and quantitative and credit easing. The latter group includes central bank's purchase of longer-term government bonds (quan- 
titative easing) or private assets such as commercial papers and mortgage backed securities (credit easing).

Two types of liquidity support policies are included, domestic currency liquidity support and foreign currency swaps. The former group consists of central bank's actions providing liquidity of domestic currency through measures such as discount rate cuts, extending maturity, creating auction facilities and expansion of the auctions, for instance. The latter group mostly consists of the US dollar liquidity-providing operations which are coordinated actions by the ECB and the FED.

Financial sector policies are classified into three types, asset purchases, liability guarantees and recapitalizations. The first group includes programs purchasing bad loans and risky assets such as mortgage backed securities from troubled financial institutions. The second group consists of policies such as establishing schemes which protect consumer deposits and guarantee debt obligations of financial institutions. The last group includes capital injections to the banks directly or indirectly through recapitalization programs.

Policy inaction and bailouts/failures are divided into three subgroups, interest rate increases/unchanged, bailouts and assisted mergers, and failures. The second and third groups include decisions to rescue (or not to rescue) particular financial institutions rather than establishing a comprehensive rescue program.

Other measures consists of other major policy announcements not included in the above groups.

Figure 1 provides a sample timeline of policy announcements.

\section{[Insert Figure 1]}

The high frequency of the various policy announcements and their overlapping nature is evident from the figure. Aït-Sahalia et al. (2012) cautions about the overlapping events in the data base which would cause an identification problem contaminating the analysis. In order to reduce the number of overlapping announcements several efforts were undertaken by them. ${ }^{1}$ In this paper we employ the main event class of policy announcements (announcements featured as a main event on the frontpage) in the database. Moreover, a one-day event window is used to further reduce the

\footnotetext{
${ }^{1}$ For instance they have employed five-day, three-day and one-day event windows showing their results are robust to the potential overlapping events problem.
} 
number of overlapping events. ${ }^{2}$

\subsection{Data}

The European and US banks included in our study are listed in Annex 1 and 2 respectively. ${ }^{3}$ Our criteria for the selection are as follows. First, we rank the European and US banks according to their total assets at the end of 2006. ${ }^{4}$ Then we extract the top one hundred banks and we keep those which are publicly traded. We repeat the same selection with end of 2010 data and hold banks which appear in both lists. After this filtering, twenty nine European banks and seventeen American banks remain in the final samples. ${ }^{5}$ Daily returns of Euro Stoxx 50 and S\&P 500 are used as proxies of the market return for the European and US markets respectively.

The overall test period is extends from 01.03.2005 to 10.14.2011. We further define the crisis period as the period covering the announcement data. Aït-Sahalia et al. (2012) refer the onset of the crisis to Nowak et al. (2011) who find a structural break in the bond market data in June 2007 and the end to the G20 Leaders' Summit held in London on 04.02.2009. Lehman's bankruptcy is widely accepted as perhaps the most dramatic crisis event that changed drastically market expectations. Hence, we use this event to subdivide our data. To summarize, our test period covers the following distinct four subperiods:

· tranquil period (01.03.2005 - 05.31.2007);

· pre-Lehman period (06.01.2007 - 09.12.2008);

· post-Lehman period (09.15.2008 - 03.31.2009);

- recovering period (04.01.2009 - 10.14.2011).

Table 2 presents summary statistics for the log daily returns of three equally weighted portfolios -All banks, European banks only, and US banks only.

[Insert Table 2]

\footnotetext{
${ }^{2}$ We have considered to use wider event windows to capture the anticipation and possible lagged effects. However the number of overlapping announcements triples from 41 to 138 if we extend to a three-day event window (1 day before and 1 day after the announcement) .

${ }^{3}$ Our sample covers all the globally systemically important financial institutions defined by the Basel committee on banking supervision in November 2011 except for Banque Populaire (a French institution not publicly traded) .

${ }^{4}$ Bankscope data are used to create the ranking.

${ }^{5}$ Although they survived the selection criteria we also eliminate from the US sample the government-sponsored enterprises such as Fannie Mae, Freddie Mac and Sallie Mae due to their particular quasi-public nature.
} 
The negative sign and the size of the mean returns (minus16 bps in the pre- and minus 67 bps in the post-Lehman periods) indicate the extent of the loss during the crisis period (06.01.2007 03.31.2009), while the widened range (1173 bps in the pre- and $3013 \mathrm{bps}$ in the post-Lehman periods) and the enlarged standard deviation of returns (188 bps in the pre- and 544 bps in the post-Lehman periods) demonstrates the volatile state of the financial markets. The standard deviation has surged more than ten-fold for the US banks from the tranquil to the post-Lehman period. Such strongly time-varying volatility would impair the results from a traditional event study approach. In order to overcome this problem we apply a GARCH-based approach suggested in the literature (Corhay and Tourani-Rad 1996, Brockett et al 1999, Savickas 2003, Balaban and Constantinou 2006).

The table also reports the return correlation between the European portfolio and the US portfolio. As it has been observed in preceding crashes the correlation has increased during the crisis period (King and Wadhwani 1990, Lee and Kim 1993, Calvo and Reinhart 1996, Baig and Goldfajn 1999, Forbes and Rigobon 2002).

The data also show a sharp increase in cross-sectional variation of individual stock return volatility during the crisis period consistent with Beltratti and Stulz (2012). The cross-sectional standard deviation of the mean returns has increased from 4 bps in the tranquil period to 10 bps in the pre-Lehman and then to 33 bps in the post-Lehman periods. In order to highlight this variation we compute the 100 days rolling window volatility of daily returns for each stock. Then for each sub-sample, European banks and US banks, and for each day, the cross-sectional standard deviations of the rolling window volatility are computed. Figure 2 plots the time series of the cross-sectional standard deviations of the rolling window volatility.

\section{[Insert Figure 2]}

The figure clearly demonstrates the strong surge of the cross-sectional variation of return volatility during the pre-Lehman period which reached a peak during the post-Lehman period. Given the strong cross-sectional variation in return volatility during the crisis period the volatility effect of policy announcement is likely not to be the same across stocks, which could produce eventinduced variance increases (Harrington and Shrider 2007). The approach we employ to overcome this problem is outlined in the next section. 


\section{Methodology}

The event study method has been commonly used to analyze market responses to the policy announcements in crisis periods (see for example, Aït-Sahalia et al., 2011, Kho et al.,2000, Miyajima and Yafeh, 2007 and Ongena et al., 2003 for example). However, the presence of heteroskedastic volatility of stock returns observed in the previous section would impair the power of the traditional tests. In order to tackle this problem we implement a variation of the generalized autoregressive conditional heteroskedasticity, GARCH (Bollerslev, 1986) -based approach suggested by Savickas (2003). More specifically, we employ the exponential generalized autoregressive conditional heteroskedasticity (EGARCH) model to allow for asymmetric effects between positive and negative returns (Nelson, 1991).

As in the traditional event study methodology we relate the daily $\log$ return of stock $i, r_{i t}$, to the daily log return of the market portfolio, $r_{m t}$, via the market model. Then our EGARCH-based approach estimates the following model:

$$
\begin{aligned}
r_{i t} & =\phi_{0, i}+\phi_{1, i} r_{m t}+\phi_{2, i} r_{m t} D_{t}^{*}+\lambda_{r, i, j}^{k} D_{j, t}^{k}+\varepsilon_{i, t}, \quad \varepsilon_{i t}=\sigma_{i, t} e_{i t} \\
\ln \left(\sigma_{i, t}^{2}\right) & =\alpha_{0, i}+\alpha_{1, i}\left[\left|\varepsilon_{i, t-1}\right|-\gamma_{i} \varepsilon_{i, t-1}\right]+\beta_{i} \ln \left(\sigma_{i, t-1}^{2}\right)+\lambda_{v, i, j}^{k} D_{j, t}^{k}
\end{aligned}
$$

for $k=E, U S$ where policies announced by European (US) authorities are labeled as $E(U S) .\left\{e_{i t}\right\}$ is a sequence of independent and identically distributed random variables following the standard normal distribution.

$D_{t}^{*}$ is a dummy variable taking the value of 1 for the crisis period and 0 for the tranquil period. This allows the "market beta" to be dependent on the state of the economy and financial markets (McQueen and Roley 1993, Pettengill, Sundaram and Mathur 1995). In this study the crisis period is defined as 2007.06.01 to 2009.03.31 which contains the above mentioned pre- and post-Lehman periods. ${ }^{6}$ Hence, $\phi_{1, i}$ is the market beta during the tranquil period and $\phi_{1, i}+\phi_{2, i}$ is the market beta during the crisis period.

$D_{j, t}^{k}$ is a dummy variable taking the value of 1 for the type $j$ policy announcement days or 0

\footnotetext{
${ }^{6}$ Table 2 shows that the average return of sample stocks was negative during thepre- and post-Lehman periods while it was positive during the tranquil and recovery periods.
} 
otherwise. We use a one day event window [0], i.e., announcement day 0, to minimize the number of overlapping events. ${ }^{7}$ The groupings of the policy actions are as specified in the previous section.

Consequently, $\lambda_{r, i, j}^{k}$ represent the type $j$ policy announcements' average effect on bank $i$ 's stock return - the abnormal return- while $\lambda_{v, i, j}^{k}$ represents the average effect on the volatility - the event induced volatility. Unlike $\lambda_{v, i, j}^{k}$ which represents the total effect of policy announcements on volatility, since the market return is included in the equation, $\lambda_{r, i, j}^{k}$ does not represent the total effect on single stock returns. Rather, the parameters capture the part of the effect not absorbed by the market which is specific to each bank.

With each daily return series of banking stocks $i$, model (1) is estimated for each policy type $j$ for $k=E, U S$. Then we cross-sectionally test whether the banking industry specific reaction to the type $j$ policies is statistically different from zero. Hence the null hypothesis to be tested is $\lambda_{r, i, j}^{k}=0$ for the abnormal return, and $\lambda_{v, i, j}^{k}=0$ for the event induced volatility. Having included $D_{j, t}^{k}$ into the volatility equation in model (1) we are taking account of the cross-sectionally diverged event induced volatility (Savickas 2003, Harrington and Shrider 2007). Furthermore, the EGARCH set up allows each stock's volatility to behave conditionally heteroskedastic. Then, similar to the method used by Savickas the test statistic we implement for the abnormal return is:

$$
\operatorname{test}_{r, j}^{k}=\frac{\bar{S}_{r, i, j}^{k}}{s e\left(S_{r, i, j}^{k}\right)}
$$

where

$$
S_{r, i, j}^{k}=\sum_{l=1}^{L} \frac{\widehat{\lambda}_{r, i, j}^{k}}{L \sqrt{\widehat{\sigma}_{i, j, l}^{2}}}, \bar{S}_{r, i, j}^{k}=\sum_{i=1}^{N} \frac{S_{r, i, j}^{k}}{N}, \text { and } s e\left(S_{r, i, j}^{k}\right)=\sqrt{\frac{1}{N(N-1)} \sum_{i=1}^{N}\left(S_{r, i, j}^{k}-\bar{S}_{r, i, j}^{k}\right)^{2}}
$$

for $k=E, U S . L$ is the number of type $j$ policy announcements, $\widehat{\lambda}_{r, i, j}^{k}$ is the estimate of $\lambda_{r, i, j}^{k}$, and $\widehat{\sigma}_{i, l}$ is the estimated conditional standard deviation of abnormal return on event day $l$. Similarly, the statistical significance of event induced volatility is tested with a variant of the test statistic

\footnotetext{
${ }^{7}$ To examine the reactions of European banking stocks to policy actions taken by the US authorities and considering the time difference between the two sides of the Atlantic the one day event window is set to [+1] (i.e., announcement day +1$)$. Furthermore, when the news is announced in the weekend the event day is postponed to the following Monday for our estimation.
} 
introduced by Balaban and Constantinou (2006):

$$
\operatorname{test}_{v, j}^{k}=\frac{\bar{S}_{v, i, j}^{k}}{\operatorname{se}\left(S_{r, i, j}^{k}\right)}
$$

where

$$
S_{v, i, j}^{k}=\frac{\widehat{\lambda}_{v, i, j}^{k}}{\sqrt{\widehat{h}_{i}}}, \bar{S}_{v, i, j}^{k}=\sum_{i=1}^{N} \frac{S_{v, i, j}^{k}}{N} \text {, and } s e\left(S_{r, i, j}^{k}\right)=\sqrt{\frac{1}{N(N-1)} \sum_{i=1}^{N}\left(S_{v, i}^{k}-\bar{S}_{v, i, j}^{k}\right)^{2}}
$$

for $k=E, U S . \widehat{h}_{i}$ is the standard deviation of the estimated conditional standard deviation series for bank $i$. The test statistics are Student- $t$ distributed with $N-1$ degrees of freedom.

\section{Empirical Results}

We first use the overall crisis period (06.01.2007 - 03.31.2009), and then the post-Lehman subperiod (09.15.2008 - 03.31.2009) to examine how the European and the US policy announcements impact stock returns and volatility. We end the section with a comparison of the impact of policy announcements on the European banks and the US banks.

\subsection{European policy vs US policy: Overall crisis period}

We start our analysis with the policy announcements during the crisis period (06.01.2007 - 03.31.2009) for all banks. In Table 3, we report the cross-sectional average of the estimated abnormal returns,

$\lambda_{r, i, j}^{k}$, and that of induced volatility, $\lambda_{v, i, j}^{k}$, from the maximum likelihood estimation of equation (1) for each policy group.

[Insert Table 3]

For ease of interpretation, while we use $\bar{S}_{r, i, j}^{k}$ of equation (3) to construct the significance test, the numbers reported in Table 3 are based on the cross sectional mean of policy effect estimates.

In the first and the second column we calculate the average of the estimated abnormal returns observed on the European and the US policy announcement days, respectively. In the third column 
we subtract the two figures (European policy - US policy). $\Delta_{r}^{A}$ then represents the different reactions between the European and the US policy announcements.

Overall it appears that US policy announcements had a stronger impact on the banking industry than European policy announcements. US policy announcements were significantly stronger than European ones for four policy types compared to only one policy type where the inverse holds true. In particular, the announcements of monetary policies and financial sector policies by the US authorities were accompanied by higher abnormal returns. The exceptional case is the announcements by the European authorities concerning asset purchases which outperformed that of the US authorities by $1.76 \%$ on average. It seems that the announcements of the US liability guarantees had the most favorable impact on the banking stock returns during the crisis. Turning our attention now to the standalone reactions to the individual policy types the following observations can be made.

Fiscal Policy Several stimulus plans, three by the European and six by the US government, were announced during the crisis. The banking stocks did not react significantly to these fiscal policy measures. This is probably because the direct effects on the banking industry were not clear due to the contents of the stimulus packages such as job creation, tax cut and infrastructure spending.

Monetary Policy Reductions of the target for the US federal funds rate are accompanied by significant abnormal returns. They exceed 20 basis points on the day of the announcement (the following day for the European banks). On the other hand, the announcements of a decrease in the refinancing rate by the European Central Bank (ECB) or/and a reduction of the official bank rate by the Bank of England (BoE) were not associated with a significant abnormal return. The significantly negative $\Delta_{r}^{A}$ implies that the interest rate cut decisions by the Federal Reserve Board (FRB) had a considerably larger impact on banking stock prices than similar decisions by the European central banks. This difference could be partially attributed to how drastically the central banks reduced the target rate. On one hand, the Federal Open Market Committee has maintained the so-called zero interest rate since December 16th 2008. On the other hand, ECB (BoE) maintained it to $2.5 \%(2.0 \%)$ on December 4th 2008 and since then gradually decreased it toward $1.5 \%(1.0 \%)$. 
The quantitative and credit easing policy announcements by the FRB had a weakly significant impact of 38 basis points. The largely negative $5.83 \%$ average abnormal return on days which European authorities announced their quantitative and credit easing policies needs a careful interpretation since the effect of the policy announcement was probably distorted by other confounding announcements. ${ }^{8}$

Liquidity Support Neither the domestic channel nor the foreign currency swaps channel are accompanied by significant abnormal returns. Although not statistically significant such policies announced by the US authority had a more favorable impact than the European authorities on average.

Financial Sector Policies The reported significant average abnormal return of $-1.32 \%$ on the announcement days of US asset purchase programs could be due to the political disagreement and/or uncertainty of how the bill would be implemented and/or a discouraging monthly jobs report released on the same date. The asset purchase programs announced by the European authorities were accompanied by positive abnormal returns on average. ${ }^{9}$ The significantly positive $\Delta_{r}^{A}$ implies that the news on European asset purchase programs were absorbed by the market more favorably.

Conversely, the impact of liability guarantee by the US government was significantly larger than the respective impact of European policies. While the European policies were not effective enough to surmount negative news the US policy announcements were accompanied by a 73 basis points abnormal return on average which was the largest favorable effect among all twelve policy classes.

The average abnormal return following the US announcements of recapitalization was positive and significantly larger than the reaction following the European announcements. Such announcements by European authorities were associated with an 80 basis points negative abnormal return, which could be due to the disturbing news on the huge loss faced by RBS.

\footnotetext{
${ }^{8}$ There are only two policy announcements recorded as quantitative and credit easing in the database. On one of the announcement days, "RBS said it expects to report a 2008 loss of GBP 22 billion to GBP 28 billion (Wall Street Journal, 20 January 2009)" and hence the entire banking industry was largely shocked. It seems that the news of setting up an asset purchase programme by the BoE was not strong enough to overcome the discouraging news from RBS.

${ }^{9}$ Although it is not statistically significant, considering that the announcement effect is distorted by the disturbing news of a huge loss by RBS, its favorable impact could be not negligible.
} 
Policy Inaction and Failures/Bailouts Abnormal returns of positive 29 and 35 basis points followed the interest rate increases/unchanged by the European monetary authorities and the FRB, respectively. The market could perceive such policy inactions as central bank's confirmation of a better outlook for the banking industry.

News about bailouts and assistant mergers were not accompanied by significant abnormal returns. By contrast, the average abnormal returns following the US news about bank failures was significantly positive, which is hard to interpret. ${ }^{10}$

Volatility Effects In the fourth and fifth column of Table 3 we report the cross-sectional average of the event induced volatility estimates for the European and the US policy announcements from the maximum likelihood estimation of model (1). In the sixth column we present their difference. $\Delta_{v}^{A}$ therefore, represents the difference in the volatility effects between the European and the US policy announcements. The results show that all types of policy announcements -regardless of which side of the Atlantic the news arrived from- increased return volatility. Our results lend additional support to the literature documenting event-induced volatility increases (Savickas 2003, Harrington and Shrider 2007). The clear cut result suggests that it was extremely difficult for policy makers to provide stability in the market during the crisis period. We do not find any statistically significant $\Delta_{v}^{A}$ which indicates that the magnitude of induced volatilities was similar for the European and the US policy announcements.

\subsection{European policy vs US policy: Post-Lehman period}

Consistent with Aït-Sahalia et al. (2012), we expect market response to policy announcements to depend on the stage of the crisis. Thus we next focus on the impact of policy announcements during the post-Lehman period (09.15.2008 - 03.31.2009). We report the results in Table 4 .

[Insert Table 4]

\footnotetext{
${ }^{10}$ European stocks have surged on the following day of the announcement of the failure of IndyMac. According to Dow Jones, it was because of the "news from the U.S. that the Federal Reserve and Treasury will offer a lifeline of fresh credit to mortgage financiers Fannie Mae and Freddie Mac ... Banks were also boosted after Banco Santander confirmed an all-share deal of GBP1.3 billion for Alliance \& Leicester (Dow Jones 2008.07.14)." Moreover, both the European and the US markets reacted positively after the announcement of the failure of the NetBank. This could be because of the optimisitic statement made by the FDIC that "In good times as well as in bad, banks have failed ... It wouldn't be realistic to say that there will be absolutely no more failures, but the vast majority of banks will be able to withstand any problems because of their near historically high capitalization (The Wall Street Journal 2007.09.30)."
} 
On the whole, the US policy announcements seem to have more positive effects than the European policies which confirms the results presented above. In five cases $\Delta_{r}^{A}$ are negative and statistically significant at the $5 \%$ level (four of them are significant at the $1 \%$ level) while in two cases the $\Delta_{r}^{A}$ are positive and significant.

In contrast to the result based on the entire crisis period, $\Delta_{r}^{A}$ for bailouts and assisted mergers turned positive and highly significant. The different reactions of the market could be because many of the actions categorized as bailouts and assisted mergers taken by the European authorities during the post-Lehman period were bailouts (e.g. Fortis and Hypo Real Estate rescued 09.29.2008; Dexia rescued 09.30.2008), while many of those taken by the US government were assisted mergers (e.g. Merrill Lynch sale to Bank of America 09.15.2008; WaMu purchased by JPMorgan 09.15.2008; Wells Fargo's purchase of Wachovia 10.12.2008). The series of announcements concerning reorganizations of the US financial industry appears to be absorbed as negative news by the market.

Turning our attention now to the standalone reactions to the individual policy types, all US policy announcements on monetary policies, liquidity supports, and financial sector policies - except asset purchases - are associated with positive abnormal returns on average. Among them, four cases show a larger reaction -e.g. 265 basis points increase of foreign currency swaps case- compared to our previous estimation results which may imply that the impact of such policy announcements by the US authorities had strengthened after the bankruptcy of Lehman Brothers. ${ }^{11}$ In contrast, we do not find any statistically significantly positive abnormal returns accompanied by such policy announcements by the European authorities; five of them were negative on average (three of them are highly significant at the $1 \%$ level). This may imply that the announced contents of the European policies could not positively surprise the market enough and thereby its favorable impact did not exceed the discouraging outlook for the banking industry.

Although for few cases the average induced volatility show negative signs all of the statistically significant ones are positive. The insignificant $\Delta_{v}^{A}$ s show that there was no difference in the size of induced volatility by the European policies and the US policies on average, consistent with the findings during the entire crisis period.

\footnotetext{
${ }^{11}$ Note that there is no sample policy announcements for three categories - quantitative and credit easing, asset purchases, and recapitalization-during the pre-Lehman period. Hence the estimation results for those three policy types reported in Table 4 are the same as in Table 3.
} 


\subsection{European banks vs US banks}

We next explore the possibly different reactions of the European banking stocks and the US banking stocks to same type of policy announcements during the post-Lehman period. For each subsample we test the statistical significance of the abnormal returns with the same approach applied in the previous section. Here we focus on the abnormal returns corresponding to the announcements of monetary policies, liquidity supports and financial sector policies which are mostly system-wide measures and are accompanied by significant impacts as seen in the previous section.

[Insert Table 5]

Panel A in Table 5 reports the cross-sectional average of the abnormal returns and of the induced volatility for the European banks, while Panel B reports those for the US banks. For three cases the US policy announcements were perceived more favorably by the European markets (Panel A) and US markets (Panel B) compared to the European policy announcements at the $1 \%$ significance level. On the other hand, there is only one case where the European policy announcements were perceived more favorably by European markets. The results suggest that the US announcements impact the behavior of stock prices of both sides of the Atlantic but not vice versa. The findings are in line with the literature documenting that the US news affect the behavior of asset prices around the world but that the opposite is not true (Andersen et al. 2003, Becker et al. 1995, Ehramann and Fratzscher 2003, Wongswan, 2006).

Finally we take in account the role of expectations or market anticipation to the announcements which can potentially be important. We address this potential problem by examining the differential reactions of European and US banking stocks to the same policy announcements. It is assumed that differential reactions to the same announcement would neutralize any market anticipations if these anticipations are wide-spread.

[Insert Table 6]

The differences in reactions are reported in Table 6 . The first column in the table subtracts the first column of Panel B from the first column of Panel A in Table 5. It represents the difference in the abnormal returns between European and US banks $\left(\Delta_{r}^{B}\right)$ following the European policy 
announcements. The second column repeats the same for the US policy announcements. ${ }^{12}$ We do not find any significantly negative difference, $\Delta_{r}^{B}$, for the European policies even at the $10 \%$ level; five cases exhibit a positive sign (two of them are statistically significant at the $5 \%$ level). On the other hand, we find a significantly positive difference, $\Delta_{r}^{B}$, for the US policies at the $1 \%$ level; three cases exhibit a positive sign while four cases exhibit a negative sign (one is significant at the $10 \%$ level). Overall, the results may imply that the US policy announcements might have stronger effect on either market on average, while the European policy announcements tend to have stronger effects only on the European stock returns which is consistent with the findings in the previous section.

\section{Conclusion}

The main goal of this paper is to study how the stock markets - banking stocks in particularperceived the policy actions from the two sides of the Atlantic around the subprime crisis. To that end we use the policy news database constructed by Aït-Sahalia et al. (2012) to investigate the abnormal returns and the induced volatilities corresponding to key policy announcements by US and European authorities. The sample banks consist of systemically important institutions across Europe and US. The dynamics of the sample stock prices during the crisis period indicate strong heteroskedastic volatility and cross-sectionally diverged volatility, which would impair the power of the traditional event study to test the existence of abnormal returns. We use an EGARCHmodel with event induced volatility which allows the test statistic to be correctly adjusted for these problems.

Our finding suggest that overall US policy announcements had a stronger impact on the European and US banking industry than European policy announcements. In particular, the announcements of monetary policies and financial sector policies by the US authorities were accompanied by higher abnormal returns compared to related announcements of European authorities while the announcements of the US liability guarantees had the most favorable impact on the banking stock returns during the crisis. The lead role of US policies compared to European policies was strength-

\footnotetext{
${ }^{12} \Delta_{r}^{B}$ with a positive sign in the first column indicates that the European policy announcements had a stronger effect on the European stock returns; a negative sign indicates the opposite, their impact was stronger on the US stock returns. On the other hand, $\Delta_{r}^{B}$ with a positive sign in the second column indicates that the US policy announcements had a stronger effect on the European stock returns; a negatives sign indicates the opposite.
} 
ened after the collapse of Lehman brothers. Finally, we also find that the policy announcements, regardless of which side of the Atlantic the news arrived from, has increased the return volatility during the crisis. Our results lend additional support to the literature documenting event-induced volatility increases (Savickas 2003, Harrington and Shrider 2007).

Our findings do not provide strong direct indications of the level of the policy impacts and indeed there are several caveats that deserve mention. First, we observe some negative abnormal returns which are counter intuitive considering that policy actions are attempts to provide a positive impact. For instance, it is hard to reason that monetary policies such as interest rate cuts have a negative effect on the state of banking industry. Hence, it is likely that the observed negative abnormal return is a consequence of distortional effects delivered by other factors (e.g., negative news arrival) rather than the announced policy itself.

Second, expectations or market anticipation to the announcements can potentially be very important. We address this problem by examining the differential reactions of European and US banking stocks, $\Delta_{r}^{B}$, assuming that differential reactions would neutralize any market anticipations if these anticipations are wide-spread.

Third, our analysis suffers from cross-sectional event date clustering. As the literature has pointed out (e.g., Kolari and Pynnönen 2010), since the event day is the same for sample stocks cross-sectional correlation among abnormal returns may create statistical issues. Kolari and Pynnönen (2010) proposed a cross-correlation and volatility-adjusted version of Boehmer, Musmeci and Poulsen (1991) test statistic. While their statistic is robust to induced volatility and crosscorrelation it does not adjust for the serial heteroskedasticity which we can accommodate by utilizing an EGARCH model.

Lastly, this study does not provide an analysis on he long-term effectiveness of policies. Instead, it is an investigation of immediate market responses to policy announcements. Some policies may have been difficult to assess by the market in the short-term. For instance, announcements on unconventional measures such as the US asset purchasing program were accompanied by negative immediate responses by the banking stocks which could reflect the uncertainty of how the bill would be used. But of course it does not necessarily mean that the program had a long-term negative effect. Literature studying the long-term effect of policies extends the event window to analyze cumulative abnormal returns (e.g. King (2009) uses 100 days event window). However, 
this approach would bring another problem of "event window contamination," i.e., multiple events during the same event window.

Nevertheless these limitations are common in the literature studying market reactions to policy announcements with an event study approach. In particular, the overlapping event problem is unavoidable when using data in daily frequency. ${ }^{13}$

A more difficult and interesting question we have not addressed in this study is whether the banking stocks reacted to the content of the policy announcements and/or to the (mainly negative) economic outlook provided together with the announcements during the subprime crisis. We leave this interesting topic for future research. ${ }^{14}$

\footnotetext{
${ }^{13}$ Recent literature analyzes market reponses to news using intra day data. See for example Andersen, Bollerslev, Diebold and Vega (2003, 2007), Faust, Rogers, Wang and Wright (2007), Conrad and Lamla (2010), Rosa (2011).

${ }^{14}$ The communication by the Central Bank has been studied by e.g., Born, Benjamin, Michael Ehrmann and Marcel Fratzscher (2011).
} 


\section{References}

Aït-Sahalia, Yacine, Jochen Andritzky, Andreas Jobst, Sylwia Nowak, and Natalia Tamirisa (2012). "Market Response to Policy Initiatives during the Global Financial Crisis," Journal of International Economics forthcoming.

Andersen, Torben G., Tim Bollerslev, Francis X. Diebold and Clara Vega (2003). "Micro effects of macro announcements: Real-time price discovery in foreign exchange," American Economic Review 93, 38-62.

Andersen, Torben G., Tim Bollerslev, Francis X. Diebold and Clara Vega (2007). "Real-time price discovery in global stock, bond and foreign exchange markets," Journal of International Economics 73, 251-277.

Baba, Naohiko and Frank Packer (2009). "From turmoil to crisis: dislocations in the FX swap market before and after the failure of Lehman Brothers," Bank for International Settlements Working Paper No.285.

Baig, Taimur and Ilan Goldfajn (1999). "Financial Market Contagion in the Asian Crisis," IMF Staff Papers.46, 167-195.

Balaban, Ercan and Charalambos Th. Constantinou (2006). "Volatility Clustering and EventInduced Volatility: Evidence from the UK Mergers and Acquisitions," The European Journal of Finance 12:5, 449-453.

Beltratti, Andrea and René Stulz (2012). "The credit crisis around the globe: Why did some banks perform better?" Journal of Financial Economics 105, 1-17.

Becker, Kent G., Joseph E. Finnerty and Joseph Friedman (1995). "Economic news and equity market linkages between the US and UK," Journal of Banking and Finance 19, 1191-1210.

Bollerslev, Tim (1986). "Generalized Autoregressive Conditional Heteroskedasticity," Journal of Econometrics 31, 307-327.

Boehmer, Ekkehart, Jim Masumeci and Annette B. Poulsen (1991). "Event Study Methodology Under Conditions of Event Induced Variance," Journal of Fiancial Economics 30, 253-72.

Born, Benjamin, Michael Ehrmann and Marcel Fratzscher (2011). "Central Bank Communication on Financial Stability," ECB Working Paper Series No 1332.

Brockett, P., H. Chen and J. Garven (1999). "A new stochastically flexible event methodology with application to Proposition 103," Insurance, Mathematics and Economics 25, 197-217.

Calvo, Sara and Carmen Reinhart (1996). "Capital Flows to Latin America: Is There Evidence of Contagion Effects?" World Bank Policy Research Working Paper 1619.

Conrad, Christian and Michael J. Lamla (2010). "The High-Frequency Response of the EURUSD Exchange Rate to ECB Communication," Journal of Money, Credit and Banking 42, 1391-1417.

Corhay, Albert. and Tourani-Rad Alireza (1996). "Conditional heteroskedasticity adjusted market model and an event study," The Quarterly Review of Economics and Finance 36, 529-538. 
Ehrmann, Michael and Marcel Fratzscher (2003). "Interdependence between the euro area and the US: What role for EMU?" European Central Bank Working Paper No. 200.

Faust, Jon, John H. Rogers, Shing-Yi B. Wang and Jonathan H. Wright (2007). "The highfrequency response of exchange rates and interest rates to macroeconomic announcements," Journal of Monetary Economics 54, 1051-1068.

Forbes, Kristin J. and Roberto Rigobon (2002). "No Contagion, Only Interdependence: Measuring Stock Market Comovements," Journal of Finance 57, 2223-2261.

Harrington, Scott E. and David G. Shrider (2007). "All Events Induce Variance: Analyzing Abnormal Returns When Effects Vary across Firms," Journal of Financial and Quantitative Analysis 42, 229-256.

Kho, Bong-Chan, Dong Lee and René M. Stulz (2000). "U.S. Banks, Crises, and Bailouts: From Mexico to LTCM," American Economic Review 90, 28-31.

King, Michael R (2009). "Time to buy or just buying time? The market reaction to bank rescue packages," BIS Working Papers 288.

King, Mervyn A. and Sushil Wadhwani (1990). "Transmission of Volatility between Stock Markets," The Review of Financial Studies 3, 5-33.

Kolari, James W. and Seppo Pynnönen (2010). "Event Study Testing with Cross-sectional Correlation of Abnormal Returns," The Review of Financial Studies 23, 3996-4025.

Lee, Sang B. and Kwang Jung Kim (1993). "Does the October 1987 crash strengthen the comovements among national stock markets?" Review of Financial Economics 3, 89-102.

McAndrews, James, Asani Sarkar and Zhenyu Wang (2008). "The Effect of the Term Auction Facility on the London Inter-Bank Offered Rate," Federal Reserve Bank of New York Staff Report No.335.

McQueen, Grant and V. Vance Roley (1993). "Stock Prices, News, and Business Conditions," The Review of Financial Studies 6, 683-707.

Miyajima, Hideaki and Yishay Yafeh (2007). "Japan's banking crisis: An event-study perspective," Journal of Banking and Finance 31, 2866-2885.

Nelson, Daniel B. (1991). "Conditional Heteroskedasticity in Asset Returns: A New Approach," Econometrica 59, 347-370.

Nowak, Sylwia, Jochen Andritzky, Andreas Jobst and Natalia Tamirisa (2011). "Macroeconomic fundamentals, price discovery, and volatility dynamics in emerging bond markets," Journal of Banking and Finance 35, 2584-2597.

Ongena, Steven, David C. Smith and Dag Michalsen (2003). "Firms and their distressed banks: lessons from the Norwegian banking crisis," Journal of Financial Economics 67, 81-112.

Panetta, Fabio, Thomas Faeh, Giuseppe Grande, Corrine Ho, Michael King, Aviram Levy, Federico M Signoretti, Marco Taboga and Andrea Zaghini (2009). "An assessment of financial sector rescue programmes," Bank for International Settlements Working Paper No.48. 
Pettengill, Glenn N., Sridhar Sundaram and Ike Mathur (1995). "The Conditional Relation between Beta and Returns," The Journal of Financial and Quantitative Analysis 30, 101-116.

Rosa, Carlo (2011). "The high-frequency response of exchange rates to monetary policy actions and statements," Journal of Banking and Finance 35, 478-489.

Savickas, Robert (2003). "Event-Induced Volatility and Tests for Abnormal Performance," The Journal of Financial Research 26, 165-178.

Taylor, John B. and John C. Williams (2009). "A black swan in the money market," American Economic Journal: Macroeconomics 1 (1), 58-83.

Wongswan, Jon (2006). "Transmission of Information across International Equity Markets," Review of Financial Studies 19, 1157-1189. 
Annex 1

List of Banks and their Total Assets: Europe

\begin{tabular}{llrr}
\hline Bank Name & $\begin{array}{l}\text { Country } \\
\text { code }\end{array}$ & $\begin{array}{r}\text { Total Assets } \\
\text { (mil \$) 2006 }\end{array}$ & $\begin{array}{r}\text { Total Assets } \\
\text { (mil \$) 2010 }\end{array}$ \\
\hline \hline BNP Paribas & FR & $1,896,935$ & $2,669,907$ \\
Deutsche Bank AG & DE & $2,070,022$ & $2,546,272$ \\
HSBC Holdings Plc & GB & $1,860,758$ & $2,454,689$ \\
Barclays Plc & GB & $1,956,710$ & $2,331,943$ \\
Royal Bank of Scotland Group Plc & GB & $1,710,636$ & $2,275,479$ \\
Crédit Agricole S.A. & FR & $1,660,125$ & $2,129,248$ \\
ING Groep NV & NL & $1,615,049$ & $1,666,368$ \\
Banco Santander SA & ES & $1,098,212$ & $1,626,805$ \\
Lloyds Banking Group Plc & GB & 674,489 & $1,552,245$ \\
Société Générale & FR & $1,260,162$ & $1,512,656$ \\
UBS AG & CH & $1,922,775$ & $1,401,923$ \\
UniCredit SpA & IT & $1,084,267$ & $1,241,966$ \\
Credit Suisse Group AG & CH & $1,029,219$ & $1,098,345$ \\
Commerzbank AG & DE & 801,184 & $1,007,882$ \\
Intesa Sanpaolo & IT & 759,626 & 880,221 \\
Nordea Bank AB (publ) & SE & 456,855 & 776,108 \\
Dexia & BE & 746,402 & 757,262 \\
Banco Bilbao Vizcaya Argentaria SA & ES & 542,495 & 738,560 \\
Natixis & FR & 604,021 & 611,984 \\
Danske Bank A/S & DK & 483,866 & 572,548 \\
Standard Chartered Plc & GB & 266,047 & 516,542 \\
KBC Groep NV / KBC Groupe SA & BE & 428,553 & 428,679 \\
Banca Monte dei Paschi di Siena SpA & IT & 208,818 & 326,402 \\
Skandinaviska Enskilda Banken AB & SE & 281,808 & 324,876 \\
Crédit Industriel et Commercial & FR & 282,251 & 323,405 \\
Svenska Handelsbanken & SE & 260,767 & 320,958 \\
DnB ASA & NO & 210,901 & 316,183 \\
Deutsche Postbank AG & DE & 243,497 & 286,857 \\
Erste Group Bank AG & AT & 239,304 & 275,171 \\
\hline
\end{tabular}

The table reports total assets of the 29 banks at the end of years 2006 and 2010 (in US dollars). Data is collected from Bankscope. The country codes are as follows. AT: Austria; BE: Belgium; CH: Switzerland; DE: Germany; DK: Denmark; ES: Spain; FR: France; GB: United Kingdom; IT: Italy; NL: Netherlands; NO: Norway; SE: Sweden. 
Annex 2

List of Banks and their Total Assets: United States

\begin{tabular}{lrr}
\hline Bank & $\begin{array}{r}\text { Total Assets } \\
\text { (mil \$) 2006 }\end{array}$ & $\begin{array}{r}\text { Total Assets } \\
\text { (mil \$) 2010 }\end{array}$ \\
\hline \hline Bank of America Corporation & $1,459,737$ & $2,264,909$ \\
JP Morgan Chase \& Co. & $1,351,520$ & $2,117,605$ \\
Citigroup Inc & $1,884,318$ & $1,913,902$ \\
Wells Fargo \& Company & 481,996 & $1,258,128$ \\
Goldman Sachs Group, Inc & 838,201 & 911,332 \\
Morgan Stanley & $1,120,645$ & 807,698 \\
Prudential Financial Inc & 454,266 & 539,854 \\
US Bancorp & 219,232 & 307,786 \\
PNC Financial Services Group Inc & 101,820 & 264,284 \\
Capital One Financial Corporation & 149,739 & 197,503 \\
SunTrust Banks, Inc. & 182,162 & 172,874 \\
State Street Corporation & 107,353 & 160,505 \\
BB\&T Corporation & 121,351 & 157,081 \\
American Express Company & 127,853 & 147,042 \\
Regions Financial Corporation & 143,369 & 132,351 \\
Fifth Third Bancorp & 100,669 & 111,007 \\
KeyCorp & 92,337 & 91,843 \\
\hline
\end{tabular}

The table reports total assets of the 17 banks at the end of years 2006 and 2010 (in US dollars). Data is collected from Bankscope. 


\section{Table 1}

Number of Policy Announcement Events

\begin{tabular}{|c|c|c|c|c|c|c|}
\hline & \multicolumn{2}{|c|}{ Pre-Lehman } & \multicolumn{2}{|c|}{ Post-Lehman } & \multicolumn{2}{|c|}{ Total } \\
\hline & European & US & European & US & European & US \\
\hline & Policy & Policy & Policy & Policy & Policy & Policy \\
\hline Fiscal Policy & 0 & 2 & 3 & 4 & 3 & 6 \\
\hline \multicolumn{7}{|l|}{ Monetary Policy } \\
\hline Interest rate cuts & 2 & 7 & 7 & 5 & 9 & 12 \\
\hline Quantitative and credit easing & 0 & 0 & 2 & 5 & 2 & 5 \\
\hline \multicolumn{7}{|l|}{ Liquidity Support } \\
\hline Domestic currency liquidity support & 9 & 10 & 2 & 6 & 11 & 16 \\
\hline Foreign currency swaps & 4 & 3 & 1 & 1 & 5 & 4 \\
\hline \multicolumn{7}{|l|}{ Financial Sector Policies } \\
\hline Asset Purchases & 0 & 0 & 5 & 6 & 5 & 6 \\
\hline Liability Guarantees & 4 & 1 & 15 & 7 & 19 & 8 \\
\hline Recapitalizations & 0 & 0 & 15 & 15 & 15 & 15 \\
\hline \multicolumn{7}{|c|}{ Policy Inaction and Failures/Bailouts } \\
\hline Interest rate increases/unchanged & 11 & 3 & 2 & 1 & 13 & 4 \\
\hline Bailouts and Assisted Mergers & 4 & 3 & 3 & 7 & 7 & 10 \\
\hline Failures & 0 & 2 & 0 & 1 & 0 & 3 \\
\hline Other Measures & 2 & 3 & 3 & 7 & 5 & 10 \\
\hline
\end{tabular}

The events sample is subdivided into a Pre-Lehman period (06.01.2007 to 09.12.2008) and a Post-Lehman period (09.15.2008 to 03.31.2009). 
Table 2

Summary Statistics of Daily Portfolio Returns

\begin{tabular}{lrrrr}
\hline & Tranquil & Pre-Lehman & Post-Lehman & Recovery \\
\hline \hline All Banks & & & & \\
Mean & 0.0006 & -0.0016 & -0.0067 & 0.0003 \\
Std.dev. & 0.0067 & 0.0188 & 0.0544 & 0.0205 \\
Min. & -0.0322 & -0.0456 & -0.1599 & -0.1065 \\
Max. & 0.0283 & 0.0717 & 0.1414 & 0.1084 \\
& & & & \\
European Banks & & & & \\
Mean & 0.0007 & -0.0017 & -0.0064 & 0.0001 \\
Std.dev. & 0.0081 & 0.0193 & 0.0506 & 0.0214 \\
Min. & -0.0384 & -0.0723 & -0.1189 & -0.0772 \\
Max. & 0.0305 & 0.0620 & 0.1573 & 0.1340 \\
& & & & \\
US Banks & & & & \\
Mean & 0.0003 & -0.0014 & -0.0072 & 0.0006 \\
Std.dev. & 0.0075 & 0.0268 & 0.0797 & 0.0265 \\
Min. & -0.0360 & -0.0735 & -0.2586 & -0.1729 \\
Max. & 0.0246 & 0.1448 & 0.1930 & 0.1931 \\
& & & & \\
Correlation & 0.3758 & 0.4413 & 0.5740 & 0.5438 \\
\hline
\end{tabular}

The mean, standard deviation, minimum and maximum of the log daily returns of each portfolio during each sub-period are reported. The three equally weighted portfolios consist of: All banks; European banks; US banks, respectively. The observation period is divided into: Tranquil period (01.03.2005 to 05.31.2007); Pre-Lehman period (06.01.2007 to 09.12.2008); Post-Lehman period (09.15.2008 to 03.31.2009); Recovery period (04.01.2009 to 10.14.2011). The correlation is calculated between the European and the US portfolio returns. 
Table 3

Reactions of Banking Stocks to Policy Announcements: Overall Crisis Period

\begin{tabular}{|c|c|c|c|c|c|c|}
\hline & \multicolumn{3}{|c|}{ Return } & \multicolumn{3}{|c|}{ Volatility } \\
\hline & European & US & & Europe & US & \\
\hline & Policy & Policy & $\Delta_{r}^{A}$ & Policy & Policy & $\Delta_{v}^{A}$ \\
\hline Fiscal Policy & 0.0020 & 0.0010 & 0.0010 & $0.0183^{* *}$ & $0.0199^{* *}$ & -0.0016 \\
\hline \multicolumn{7}{|l|}{ Monetary Policy } \\
\hline Interest rate cuts & -0.0023 & $0.0022^{* * *}$ & $-0.0045^{* * *}$ & $0.0265^{* *}$ & $0.0247^{* * *}$ & 0.0018 \\
\hline Quantitative and credit easing & $-0.0583^{* * *}$ & $0.0038^{*}$ & $-0.0620^{* * *}$ & $0.0067^{* *}$ & $0.0090^{* * *}$ & -0.0023 \\
\hline \multicolumn{7}{|l|}{ Liquidity Support } \\
\hline Domestic currency liquidity support & $-0.0011^{*}$ & -0.0005 & -0.0005 & 0.0060 & 0.0190 & -0.0130 \\
\hline Foreign currency swaps & 0.0000 & 0.0006 & -0.0006 & $0.0254^{*}$ & 0.0313 & -0.0059 \\
\hline \multicolumn{7}{|l|}{ Financial Sector Policies } \\
\hline Asset Purchases & 0.0044 & $-0.0132^{* * *}$ & $0.0176^{* * *}$ & $0.1147^{*}$ & $0.0100^{* *}$ & 0.1047 \\
\hline Liability Guarantees & $-0.0013^{*}$ & $0.0073^{* * *}$ & $-0.0086^{* * *}$ & $0.0222^{* *}$ & $0.0465^{* *}$ & -0.0243 \\
\hline Recapitalization & $-0.0080^{* * *}$ & 0.0017 & $-0.0097^{* *}$ & $0.0161^{* *}$ & $0.0253^{* * *}$ & -0.0092 \\
\hline \multicolumn{7}{|c|}{ Policy Inaction and Failures/Bailouts } \\
\hline Interest rate increases/unchanged & $0.0029^{* * *}$ & $0.0035^{* * *}$ & -0.0006 & $0.0319^{*}$ & 0.0449 & -0.0130 \\
\hline Bailouts and Assisted Mergers & -0.0011 & 0.0005 & -0.0016 & 0.0397 & 0.0486 & -0.0090 \\
\hline Failures & & $0.0023^{* *}$ & & & 0.0099 & \\
\hline Other Measures & 0.0003 & -0.0022 & 0.0025 & 0.0046 & $0.0274^{* *}$ & $-0.0228^{*}$ \\
\hline
\end{tabular}

The table reports the cross-sectional average of estimated abnormal returns, $\widehat{\lambda}_{r, i, j}^{E}$ and $\widehat{\lambda}_{r, i, j}^{U S}$, and that of induced volatility, $\widehat{\lambda}_{v, i, j}^{E}$ and $\hat{\lambda}_{v, i, j}^{U S}$, from the maximum likelihood estimation of equation (1) using the policy announcements during the overall crisis period (06.01.2007 - 03.31.2009). For ease of interpretation, while we use $\bar{S}_{r, i, j}^{E}, \bar{S}_{r, i, j}^{U S}, \bar{S}_{v, i, j}^{E}$, and $\bar{S}_{v, i, j}^{U S}$ of equation (3) to construct the significant test the numbers reported in the table are based on the cross sectional mean of policy effect estimates. In the 1st and the 2nd column we calculate the average of the estimated abnormal returns observed on the European and US policy announcement days respectively. In the 3rd column we subtract the two figures (European policy - US policy). $\Delta_{r}^{A}$ then represents the different reactions between the European and the US policy announcements. In the 4th and 5th column of the table we report the cross-sectional average of the event induced volatility estimates. In the 6 th column we present the difference. $\Delta_{v}^{A}$ therefore, represents the difference in the effect on volatility between the European and the US policy announcements. The estimates are statistically significant at ${ }^{*} 10 \%,{ }^{* *} 5 \%$, and ${ }^{* * *} 1 \%$, respectively. 
Table 4

Reactions of Banking Stocks to Policy Announcements: Post-Lehman Period

\begin{tabular}{|c|c|c|c|c|c|c|}
\hline & \multicolumn{3}{|c|}{ Return } & \multicolumn{3}{|c|}{ Volatility } \\
\hline & European & US & & Europe & US & \\
\hline & Policy & Policy & $\Delta_{r}^{A}$ & Policy & Policy & $\Delta_{v}^{A}$ \\
\hline Fiscal Policy & 0.0020 & -0.0096 & 0.0116 & $0.0183^{* *}$ & $0.0307^{* *}$ & -0.0124 \\
\hline \multicolumn{7}{|l|}{ Monetary Policy } \\
\hline Interest rate cuts & $-0.0051^{*}$ & $0.0048^{* *}$ & $-0.0099^{* * *}$ & $0.0129^{* *}$ & -0.0022 & 0.0151 \\
\hline Quantitative and credit easing & $-0.0583^{* * *}$ & $0.0038^{*}$ & $-0.0620^{* * *}$ & $0.0067^{* *}$ & $0.0090^{* * *}$ & -0.0023 \\
\hline \multicolumn{7}{|l|}{ Liquidity Support } \\
\hline Domestic currency liquidity support & -0.0021 & 0.0011 & -0.0031 & $0.0126^{* *}$ & 0.0385 & -0.0259 \\
\hline Foreign currency swaps & $-0.0302^{* * *}$ & $0.0271^{* * *}$ & $-0.0573^{* * *}$ & 0.0056 & 0.0381 & -0.0325 \\
\hline \multicolumn{7}{|l|}{ Financial Sector Policies } \\
\hline Asset Purchases & 0.0044 & $-0.0132^{* * *}$ & $0.0176^{* * *}$ & $0.1147^{*}$ & $0.0100^{* *}$ & 0.1047 \\
\hline Liability Guarantees & 0.0009 & $0.0126^{* * *}$ & $-0.0117^{* * *}$ & $0.0279^{* *}$ & $0.0263^{* *}$ & 0.0016 \\
\hline Recapitalization & $-0.0080^{* * *}$ & 0.0017 & $-0.0097^{* *}$ & $0.0161^{* *}$ & $0.0253^{* * *}$ & -0.0092 \\
\hline \multicolumn{7}{|c|}{ Policy Inaction and Failures/Bailouts } \\
\hline Interest rate increases/unchanged & $0.0179^{* * *}$ & -0.0053 & $0.0232^{*}$ & -0.0027 & -0.0026 & -0.0002 \\
\hline Bailouts and Assisted Mergers & $0.0063^{* *}$ & $-0.0078^{*}$ & $0.0141^{* * *}$ & 0.0401 & $0.0482^{* *}$ & -0.0081 \\
\hline Failures & & -0.0064 & & & $0.0102^{*}$ & \\
\hline Other Measures & $0.0067^{*}$ & $-0.0063^{*}$ & $0.0130^{* *}$ & $0.0281^{* *}$ & $0.0076^{* * *}$ & 0.0206 \\
\hline
\end{tabular}

The table reports the cross-sectional average of estimated abnormal returns, $\widehat{\lambda}_{r, i, j}^{E}$ and $\widehat{\lambda}_{r, i, j}^{U S}$, and that of induced volatility, $\widehat{\lambda}_{v, i, j}^{E}$ and $\hat{\lambda}_{v, i, j}^{U S}$, from the maximum likelihood estimation of equation (1) using the policy announcements during the post-Lehman period (09.15.2008 - 03.31.2009). For ease of interpretation, while we use $\bar{S}_{r, i, j}^{E}, \bar{S}_{r, i, j}^{U S}, \bar{S}_{v, i, j}^{E}$, and $\bar{S}_{v, i, j}^{U S}$ of equation (3) to construct the significant test the numbers reported in the table are based on the cross sectional mean of policy effect estimates. In the 1 st and the 2 nd column we calculate the average of the estimated abnormal returns observed on the European and US policy announcement days respectively. In the 3rd column we subtract the two figures (European policy - US policy). $\Delta_{r}^{A}$ then represents the different reactions between the European and the US policy announcements. In the 4th and 5th column of the table we report the cross-sectional average of the event induced volatility estimates. In the 6 th column we present the difference. $\Delta_{v}^{A}$ therefore, represents the difference in the effect on volatility between the European and the US policy announcements. The estimates are statistically significant at ${ }^{*} 10 \%,{ }^{* *} 5 \%$, and ${ }^{* * *} 1 \%$, respectively. 
Table 5

Reactions of European Banks and US Banks: Post-Lehman Period Panel A: European Banks

\begin{tabular}{|c|c|c|c|}
\hline & \multicolumn{3}{|c|}{ Return } \\
\hline & European & US & \\
\hline & Policy & Policy & $\Delta_{r}^{A}$ \\
\hline \multicolumn{4}{|l|}{ Monetary Policy } \\
\hline Interest rate cuts & $-0.0042^{*}$ & $0.0099^{* * *}$ & $-0.0141^{* * *}$ \\
\hline Quantitative and credit easing & $-0.0519^{* * *}$ & $0.0081^{* * *}$ & $-0.0600^{* * *}$ \\
\hline \multicolumn{4}{|l|}{ Liquidity Support } \\
\hline Domestic currency liquidity support & 0.0037 & -0.0017 & 0.0054 \\
\hline Foreign currency swaps & $-0.0332^{* * *}$ & $0.0272^{* * *}$ & $-0.0604^{* * *}$ \\
\hline \multicolumn{4}{|l|}{ Financial Sector Policies } \\
\hline Asset Purchases & 0.0021 & $-0.0139^{* * *}$ & $0.0160^{* * *}$ \\
\hline Liability Guarantees & $0.0047^{* * *}$ & $0.0071^{* * *}$ & -0.0024 \\
\hline Recapitalization & $-0.0070^{* * *}$ & -0.0005 & -0.0064 \\
\hline \multicolumn{4}{|c|}{ Panel B: US Banks } \\
\hline & \multicolumn{3}{|c|}{ Return } \\
\hline & European & US & \\
\hline & Policy & Policy & $\Delta_{r}^{A}$ \\
\hline \multicolumn{4}{|l|}{ Monetary Policy } \\
\hline Interest rate cuts & -0.0065 & -0.0038 & -0.0027 \\
\hline Quantitative and credit easing & $-0.0692^{* * *}$ & -0.0036 & $-0.0656^{* * *}$ \\
\hline \multicolumn{4}{|l|}{ Liquidity Support } \\
\hline Domestic currency liquidity support & $-0.0120^{* *}$ & $0.0057^{* *}$ & $-0.0177^{* * *}$ \\
\hline Foreign currency swaps & -0.0250 & 0.0271 & $-0.0521^{*}$ \\
\hline \multicolumn{4}{|l|}{ Financial Sector Policies } \\
\hline Asset Purchases & 0.0082 & -0.0121 & $0.0203^{*}$ \\
\hline Liability Guarantees & -0.0057 & $0.0220^{* * *}$ & $-0.0277^{* * *}$ \\
\hline Recapitalization & $-0.0097^{*}$ & 0.0055 & $-0.0152^{*}$ \\
\hline
\end{tabular}

The table reports the cross-sectional average of estimated abnormal returns, $\widehat{\lambda}_{r, i, j}^{E}$ and $\widehat{\lambda}_{r, i, j}^{U S}$, from the maximum likelihood estimation of equation (1) using the policy announcements during the post-Lehman period (09.15.2008 03.31.2009). For ease of interpretation, while we use $\bar{S}_{r, i, j}^{E}, \bar{S}_{r, i, j}^{U S}, \bar{S}_{v, i, j}^{E}$, and $\bar{S}_{v, i, j}^{U S}$ of equation (3) to construct the significant test the numbers reported in the table are based on the cross sectional mean of policy effect estimates. In the 1st and the 2nd column in Panel A we calculate the average of the estimated abnormal returns of European banking stocks observed on the European and US policy announcement days respectively. In the 3rd column we subtract the two figures (European policy - US policy). $\Delta_{r}^{A}$ then represents the different reactions between the European and the US policy announcements. Panel B repeats the same for the the US banks. The estimates are statistically significant at ${ }^{*} 10 \%,{ }^{* *} 5 \%$, and ${ }^{* * *} 1 \%$, respectively. 
Table 6

Reactions of European Banks vs US Banks: Post-Lehman Period

\begin{tabular}{lll}
\hline & \multicolumn{2}{c}{$\Delta_{r}^{B}$} \\
& $\begin{array}{l}\text { European } \\
\text { Policy }\end{array}$ & US \\
& & \\
\hline \hline Molicy \\
Interest rate cuts & 0.0023 & $0.0137^{* * *}$ \\
$\begin{array}{l}\text { Quantitative and credit easing } \\
\text { Liquidity Support }\end{array}$ & 0.0173 & 0.0117 \\
Domestic currency liquidity support & $0.0158^{* *}$ & $-0.0074^{*}$ \\
Foreign currency swaps & -0.0082 & 0.0001 \\
Financial Sector Policies & & \\
Asset Purchases & -0.0061 & -0.0018 \\
Liability Guarantees & $0.0104^{* *}$ & -0.0148 \\
Recapitalization & 0.0027 & -0.0061 \\
\hline
\end{tabular}

The table reports the cross-sectional average of estimated abnormal returns, $\widehat{\lambda}_{r, i, j}^{E}$ and $\widehat{\lambda}_{r, i, j}^{U S}$, from the maximum likelihood estimation of equation (1) using the policy announcements during the post-Lehman period (09.15.2008 03.31.2009). For ease of interpretation, while we use $\bar{S}_{r, i, j}^{E}, \bar{S}_{r, i, j}^{U S}, \bar{S}_{v, i, j}^{E}$, and $\bar{S}_{v, i, j}^{U S}$ of equation (3) to construct the significant test, the numbers reported in the table are based on the cross sectional mean of policy effect estimates. The 1st column in the table subtracts the first column of Panel B from the first column of Panel A in Table 5. It represents the difference in the abnormal returns $\left(\Delta_{r}^{B}\right)$ following the European policy announcements. The 2 nd column repeats the same for the US policy announcements. The estimates are statistically significant at ${ }^{*} 10 \%,{ }^{* *} 5 \%$, and ${ }^{* * *} 1 \%$, respectively. 


\section{Figure 1}

Sample Policy Announcements from the Two Sides of the Atlantic (2007-2009)

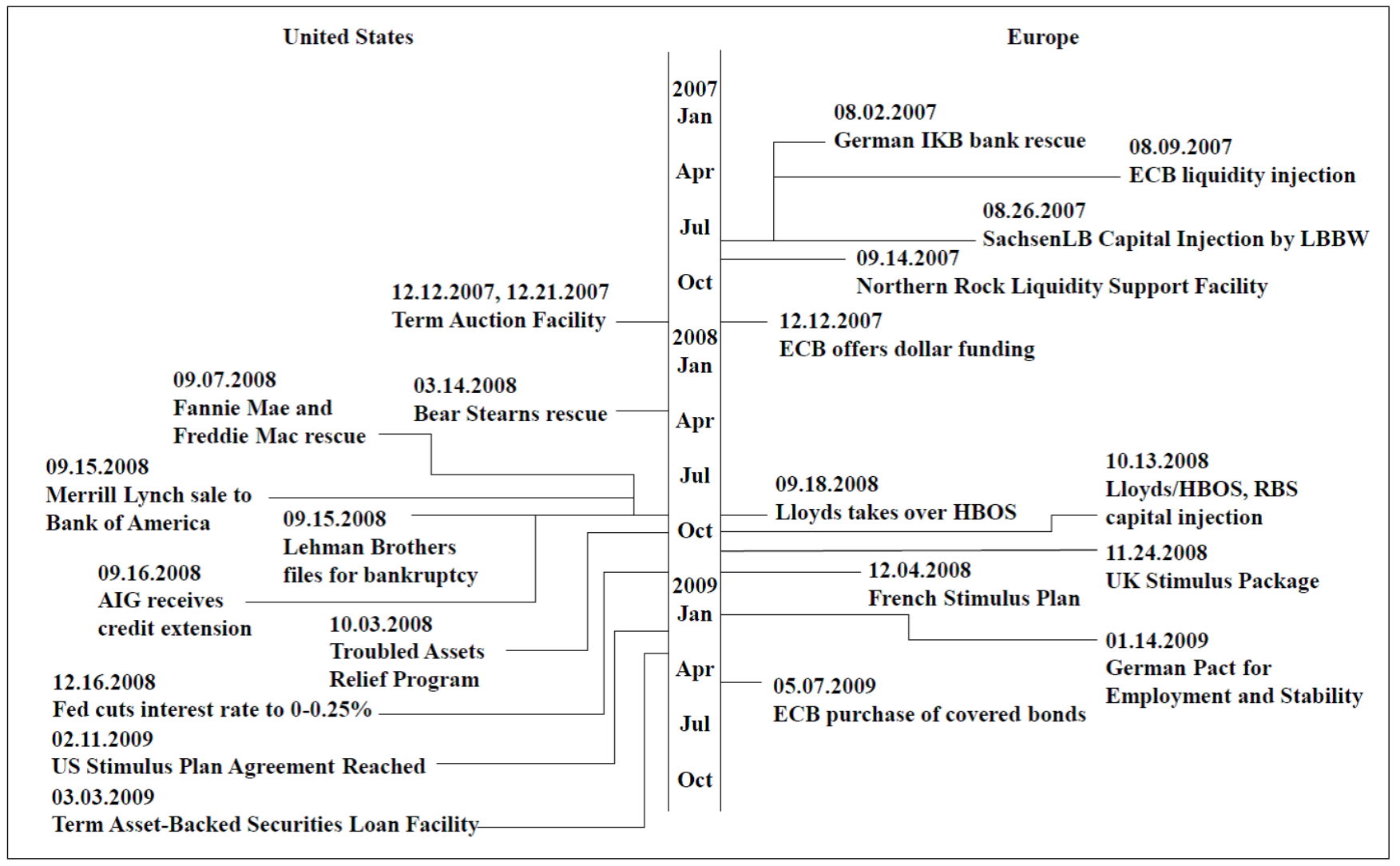

Source: Aït-Sahalia, Andritzky, Jobst, Nowak and Tamirisa (2012). 
Figure 2

Cross-sectional Standard Deviation of Return Volatility

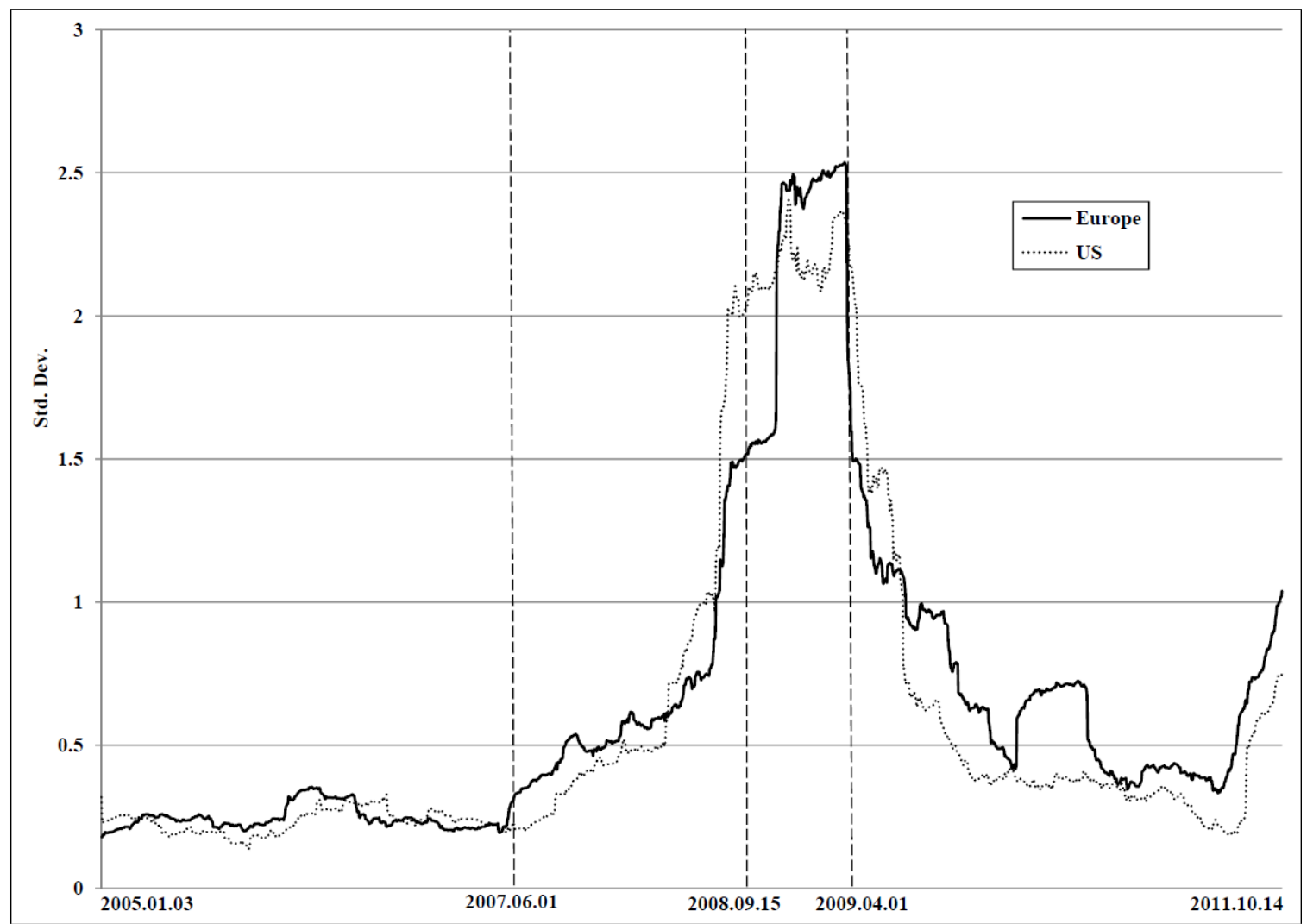

100 days rolling window volatilities of daily returns for each stock are calculated. Then for each sub-sample, the European banks and the US banks, and for each day, the cross-sectional standard deviation of the rolling window volatilities are computed. The figure plots the time series of the cross-sectional standard deviations of the rolling window volatility. 